\title{
Laboratory study of ballast material reinforced by flat geogrid under the dynamic load
}

\author{
Alexander Abrashitov ${ }^{1, *}$, and Andrei Sidrakov ${ }^{1}$ \\ ${ }^{1}$ Russian University of Transport RUT (MIIT), Obraztsova str. 9/9, 127994, Moscow, Russia
}

\begin{abstract}
Ballast material suffers from continuous degradation under cyclic load. This leads to rail track settlement and necessitates its constant maintenance. It is serious problem that costs Russia millions of dollars every year. Easily accessible plastic geogrid was proposed to reinforce ballast and to prevent its rapid degradation. However, the optimal parameters of geogrid (its mesh size, geometry and number of layers) remains an open question. In current work effects of number of geogrid layers and geogrid mesh size on ballast settlement are studied by laboratory dynamic load tests.
\end{abstract}

\section{Introduction}

Complete overhaul of $1 \mathrm{~km}$ of railway track costs about 46 million roubles or 760 thousand dollars. Renovation of ballast makes up to $25 \%$ of this sum. The average lifetime (the period during which ballast material performs its basic functions) of a new or reconstructed ballast from crushed hard stones is about 350 million tons of gross tonnage. It is significantly shorter than the lifetime of remaining elements of a railway track. Such short lifetime is explained by rapid clogging and contamination of ballast. Small particles penetrate into voids between large ballast stones and reduce ballast prism elasticity, drainage properties and porosity that finally leads to rapid settlement, loss of lateral stability and water accumulation. The main source of contamination is breakage and abrasion of ballast granules [1,2].

Since 2000 a large number of attempts have been made to increase the lifetime of ballast prism by installing flat plastic geogrid under or into ballast layer [3-6]. Reinforcement by geogrid prevents lateral displacement of particles of the granular layer under vertical load and reduces track settlement and ballast particle breakage [5]. It is achieved by partial penetration of ballast stones into geogrid holes and their adhesion to the rigid edges of the geogrid. Reinforcement of ballast prism reduces its clogging by a factor of 1.9 [3]. Moreover, the reinforced ballast shows better resistivity to degradation even in case of $40 \%$ contamination [4]. Unfortunately, researches do not have unambiguous opinion on the optimal size and geometry of geogrid mesh and number of layers $[3,5,6]$.

\footnotetext{
* Corresponding author: abr54@yandex.ru
} 


\section{Experimental part}

\subsection{Model preparation}

We prepared 5 models (non-reinforced and reinforced with different number of layers and geogrid mesh size) for dynamic load tests (Table 1). The schematic image of model is presented in Figure 1.

1. Crushed stone size distribution 25-60 mm, non-reinforced;

2. Crushed stone size distribution $25-60 \mathrm{~mm}$, reinforced with one layer of geogrid, mesh size $32 \mathrm{~mm}$;

3. Crushed stones size distribution $25-60 \mathrm{~mm}$ reinforced with two layers of geogrid, layer distance $100 \mathrm{~mm}$, mesh size $32 \mathrm{~mm}$;

4. Crushed stones size distribution $25-60 \mathrm{~mm}$ reinforced with two layers of geogrid, layer distance $100 \mathrm{~mm}$, mesh size $65 \mathrm{~mm}$;

5. Crushed stones size distribution $35-40 \mathrm{~mm}$ reinforced with three layers of geogrid, layer distance $100 \mathrm{~mm}$, mesh size $32 \mathrm{~mm}$.

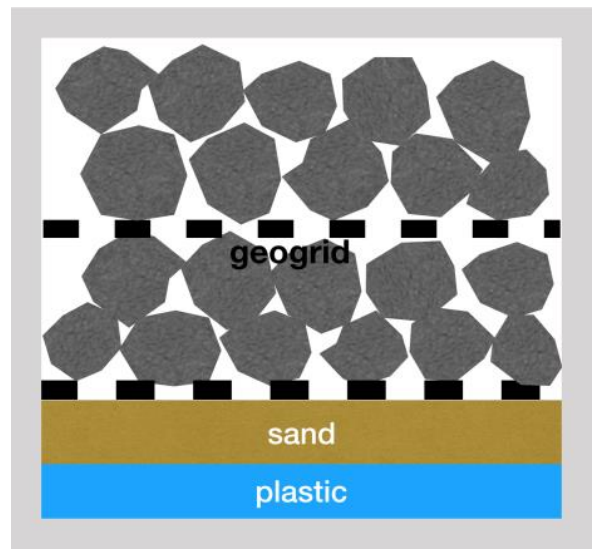

Fig. 1. Schematic view of test models.

Table 1. List of test models prepared.

\begin{tabular}{|c|c|c|c|}
\hline Model number & Particle size, $\mathrm{mm}$ & Number of geogrid layers & Geogrid mesh size, $\mathrm{mm}$ \\
\hline 1 & $25-60$ & 0 & 0 \\
\hline 2 & $25-60$ & 1 & 32 \\
\hline 3 & $25-60$ & 2 & 32 \\
\hline 4 & $25-60$ & 2 & 65 \\
\hline 5 & $35-40$ & 3 & 32 \\
\hline
\end{tabular}

The models were prepared as follows. Elastic polymer material (strain modulus 11.5 $\mathrm{MPa}$ ) imitated ground in the base of the railway track and was put into a metal box (600 $\mathrm{mm} \times 1100 \mathrm{~mm} \times 800 \mathrm{~mm}$ ). Plastic layer was followed by a sand layer from quartz sand of medium size. Sand layer was compacted by a plate compacter Zitrek CNP 10 (Figure 2, a). For non-reinforced model metal box was filled with crushed stones (GOST 7392-2014) from dense rock to imitate the ballast layer. For this purposes we filled the box with stones to form a layer with $100 \mathrm{~mm}$ thickness. This layer was also compacted by a plate compacter 
Zitrek CNP 10. The procedure was repeated 3 times. The fourth layer was not compacted. Total thickness of the stone layer was $350 \mathrm{~mm}$. In case of reinforced models plastic and sand layers were followed by geogrid layer $(1000 \mathrm{~mm} \times 550 \mathrm{~mm}$ ) (Figure 2, b). This layer was followed by stone layer of $100 \mathrm{~mm}$ thickness which was compacted according to the procedure described earlier (Figure 2, c). The other stone and geogrid layers were prepared in the same way. For the 5th model stones were preliminary sifted to achieve narrow size distribution of $35-40 \mathrm{~mm}$. The metal box was placed into the testing machine (Universal EPS test machine, GDR) (Figure 2, d). All models were pressurised with a rigid stamp $(1090 \mathrm{~mm} \times 590 \mathrm{~mm})$ over the entire surface. The pressure was $30 \mathrm{~N} / \mathrm{cm}^{2}$. It was maintained for 5 minutes. After that model settlement was measured. The procedure was repeated until the residual settlement did not go beyond $0.5 \mathrm{~mm}$.

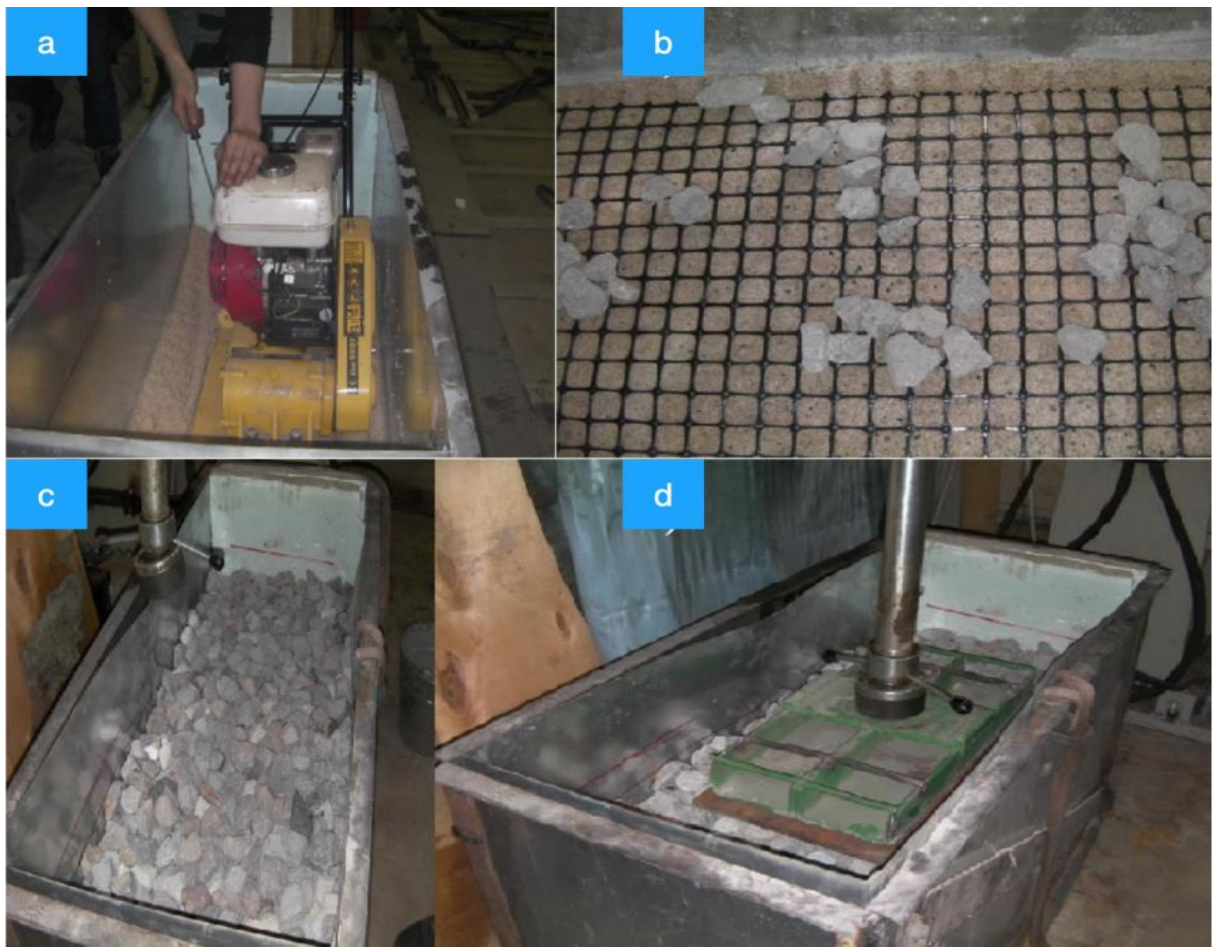

Fig. 2. a) Sand layer formation; b) Geogrid on a sand separating layer; c) Stacking and compacting of stones; d) Static compacting of stones.

\section{Results and discussion}

\subsection{Dynamic load tests}

All samples were put into the testing machine and dynamically loaded $\left(32 \mathrm{~N} / \mathrm{cm}^{2}\right)$. This value is equivalent to 25 tons per axle. The applied frequency was $6 \mathrm{~Hz}$ which corresponds to the speed of 40 kilometers per hour. The unloading value comprised $10 \%$ of maximum load. Test duration was 1 million cycles.

At first we studied influence of number of geogrid layers on the mechanical performance of test ballast models under dynamic load. The results are presented in Figure 3. It may be seen that reinforcement apparently gave positive effect on settlement. Settlement value decreased by a factor of 1.5 for reinforced samples compared to non- 
reinforced sample. However, in case of 1 geogrid layer the saturation point (a point at which further cyclic dynamic loading leads to less than $1 \mathrm{~mm}$ settlement per 100000 cycles) seem to be much further than for models with no reinforcement or with 2 layers of geogrid. This may indicate mechanical instability of ballast with 1 layer of geogrid. Model with two layer of geogrid shows good settlement value and rapidly reaches saturation of settlement under the cyclic dynamic load.

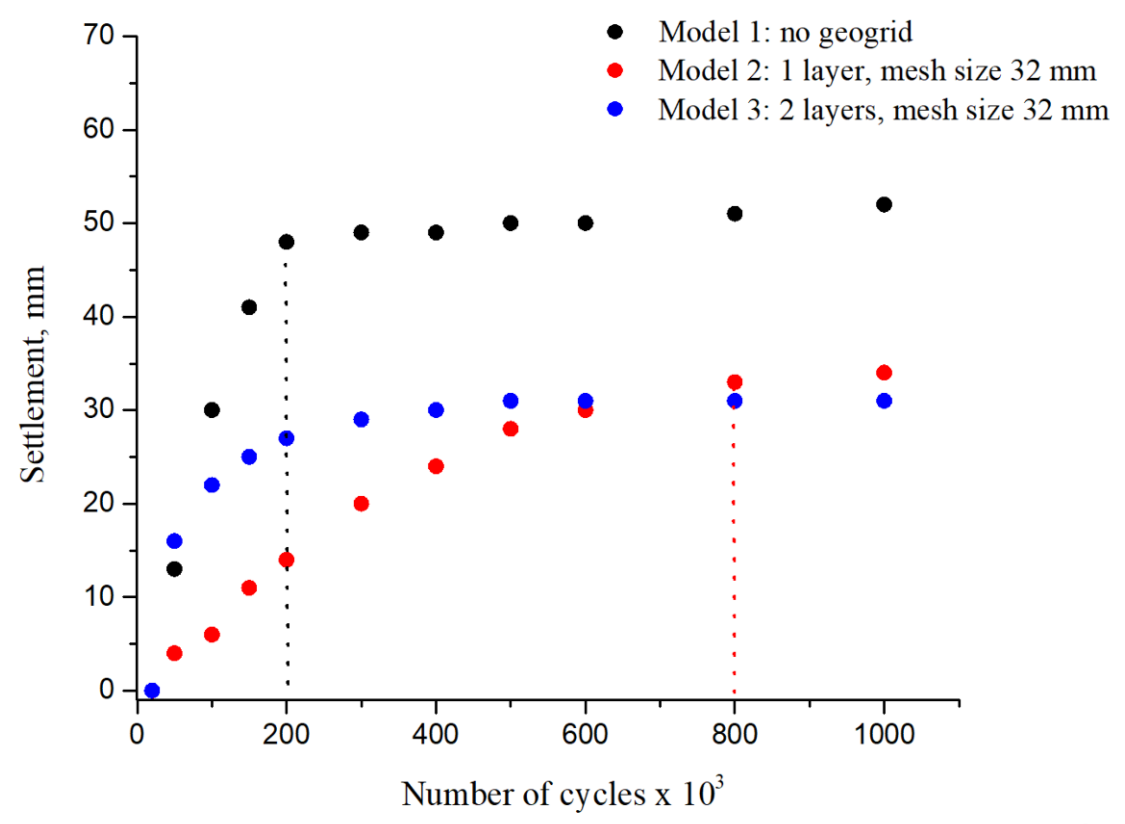

Fig. 3. Dynamic load tests of models 1-3. Non reinforced ballast is marked by black dots, ballast reinforced with 1 layer of geogrid is marked by red dots, and ballast reinforced with 2 layers of geogrid is marked by blue dots. Saturation points are marked with dotted lines.

\subsection{Dependence on the geogrid mesh size}

Then we investigated influence of geogrid mesh size on the resistance of model to dynamic loading. The results are presented in Figure 4, a. We compared two mesh sizes: $32 \mathrm{~mm}$ and $65 \mathrm{~mm}$. Both models have shown good settlement level and needed low number of cycles to achieve settlement saturation. However, in case of larger mesh size the settlement curve exhibited a break that might indicate mechanical instability. To check this assumption we prepared a fresh model and performed second test. The curve from the second test also demonstrated a break and its shape changed significantly. Non-monotonous behaviour and non-equivalence of two curves proves that model with larger geogrid mesh size is mechanically unstable. 
a)

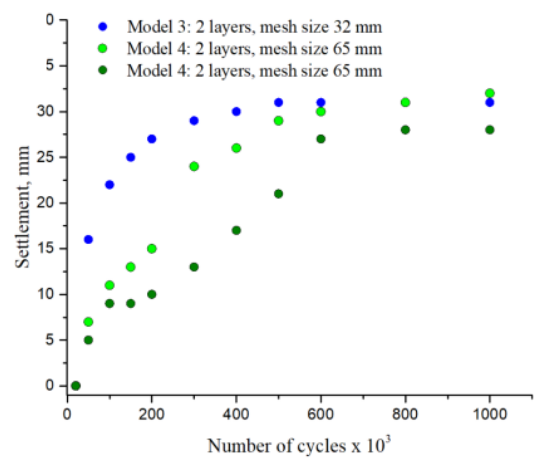

b)

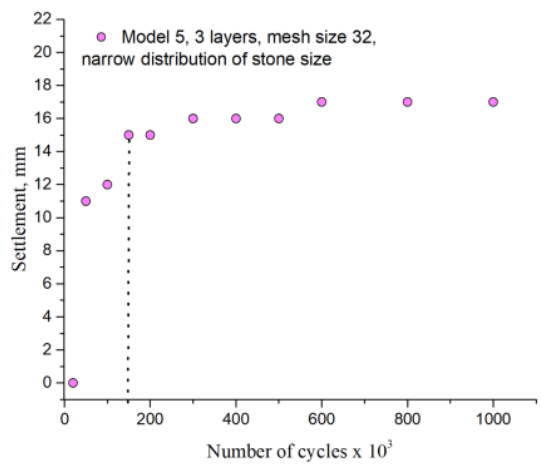

Fig. 4. a) Dynamic load tests of models 3-4. Ballast reinforced by geogrid with mesh size of $32 \mathrm{~mm}$ is marked by blue dots and Ballast reinforced by geogrid with mesh size of $65 \mathrm{~mm}$ is marked by light green and dark green dots. b) Dynamic load test of model 5 (narrow distribution of stone size).

Mechanical behaviour of stone pile of diverse form and wide size distribution is a relatively complex process. To achieve deep understanding of model response to load in dependence of model parameters it is necessary to simplify test model. For this purposes we sifted crushed stone samples to achieve narrow size distribution $35-40 \mathrm{~mm}$. This size corresponds to the largest component in the size distribution of native stone sample. Due to more dense stone packing in this case we added an additional reinforcement layer to keep the chosen geometry of ballast model $(100 \mathrm{~mm}$ distance between adjacent reinforced layers, $50 \mathrm{~mm}$ thickness of top non compacted layer). The results are presented in Figure 4, b. The decrease of both settlement level and saturation point indicate well optimized mesh size for the dominant component of stone size. However, further experiments are required to determine the geogrid geometry that will perform the most pronounced influence on ballast mechanical response.

In conclusion we performed laboratory analysis of mechanical behaviour of composite material composed of crushed stones reinforced by geogrid. The results indicate sharp dependence of overall mechanical stability and settlement level of the model on number of geogrid layers and geogrid mesh size. Further experiments will be performed to optimize and design composite material, which will be most resistant to degradation under cyclic load.

\section{References}

1. E.T. Selig, J.M. Waters, Track Geotechnology and Substructure Management (Thomas Telford London, 1994)

2. A. Abrashitov, A. Semak, Procedia engineering 189, 75 - 79 (2017)

3. C.C.J. Kwan, Geogrid reinforcement of railway ballast, PhD thesis (University of Nottingham, 2006)

4. B. Indraratnaa, N.T. Ngoa, C. Rujikiatkamjorna, Procedia engineering 189, 207 - 214 (2017)

5. Z. Rakowski, Procedia engineering 189, 166 - 173 (2017)

6. E. Tutumluer, Geogrid-aggregate interlock mechanism investigated, Special sessions on Geosynthetics in Road Construction, EuroGeo 6 (Ljubljana, 2016) 